\title{
Relation between Anterior-Posterior Foot Pressure Ratio and Kindergartens' Barefoot Policy
}

\author{
Shigeki Matsuda ${ }^{1}$, Kosho Kasuga², Tadayuki Hanai ${ }^{3}$, Tomohiro Demura ${ }^{4}$, Kanako Futabayashi ${ }^{1}$ \\ ${ }^{1}$ Faculty of Education, Shiga University, Otsu, Japan \\ ${ }^{2}$ Faculty of Education, Gifu University, Gifu, Japan \\ ${ }^{3}$ Department of Early Childhood Education, Chubu University, Kasugai, Japan \\ ${ }^{4}$ Faculty of Human Life Studies, Jin-ai University, Echizen, Japan \\ Email: ${ }^{*}$ atsuda@edu.shiga-u.ac.jp
}

How to cite this paper: Matsuda, S., Kasuga, K., Hanai, T., Demura, T., \& Futabayashi, K. (2016). Relation between AnteriorPosterior Foot Pressure Ratio and Kindergartens' Barefoot Policy. Advances in Physical Education, 6, 328-335.

http://dx.doi.org/10.4236/ape.2016.64033

Received: August 28, 2016

Accepted: October 29, 2016

Published: November 1, 2016

Copyright $\odot 2016$ by authors and Scientific Research Publishing Inc. This work is licensed under the Creative Commons Attribution International License (CC BY 4.0).

http://creativecommons.org/licenses/by/4.0/

\begin{abstract}
This study aimed at clarifying the relation between anterior-posterior foot pressure ratio and kindergartens' barefoot policy. Participants included 257 preschool children (125 boys and 132 girls) attending kindergartens with a barefoot policy and 316 preschool children (157 boys and 159 girls) attending kindergartens without this policy. An instrument called Foot view Clinic was used to measure the anteriorposterior foot pressure ratio. Participants maintained an upright posture on the instrument for 10 seconds. The posterior foot pressure proportion for each participant's feet was used to evaluate heel load, and the mean of a 10-second measurement was used for analysis. Among boys, posterior foot pressure was significantly lower for those attending kindergartens following a barefoot policy than for those attending kindergartens not following a barefoot policy. On the other hand, no significant difference was observed in the posterior foot pressure ratio between girls who played barefoot and those who did not. Therefore, in conclusion, kindergartens' barefoot policy affects children's anterior-posterior foot pressure ratio and reduces the posterior foot pressure ratio in boys.
\end{abstract}

\section{Keywords}

Preschool Children, Barefoot, Heel Load, Anterior-Posterior Foot Pressure Ratio

\section{Introduction}

Some kindergartens in Japan follow a policy according to which children play barefoot when playing indoors after arriving at their kindergartens. This barefoot policy has been adopted because of the belief that it positively affects children's health and growth by influencing the foot shape (medial longitudinal arch and foot width) and the contact 
between their toes and the ground (Asami, Ishijima, \& Shibukawa, 1990; Matsuda, Kasuga, Hanai, \& Demura, 2016; Matsuda, Kasuga, Hanai, Demura, \& Komura, 2016). However, the actual effects of kindergartens' barefoot policies, beyond their influence on the shape of children's feet and toes, have seldom been examined. Owing to the limited evidence available on the barefoot policy's benefits, there is very little consensus on this issue. Some people believe that going barefoot may increase the likelihood of injuring the contact surface area of the feet; thus, further research on the relation between barefoot policy and various foot-related factors is necessary.

As children grow older, their anterior foot pressure ratio increases while standing and therefore the tendency of the heel load changes with that of the forefoot load (Matsuda \& Demura, 2013; Usui, Maekawa, \& Hirasawa, 1995). However, it has recently been reported that some children have "untouched toes", or toes that do not touch the ground when they stand normally, and children with many untouched toes also tend to have increased heel load (Matsuda, Demura, Kasuga, \& Sugiura, 2011; Matsuda, Demura, Kasuga, \& Sugiura, 2013; Matsuda et al., 2009). Considering the natural changes in foot pressure ratio that occur with age (Matsuda \& Demura, 2013; Usui et al., 1995), a heel load tendency in early childhood is undesirable. In addition, decreased physical fitness, deterioration of posture, and rapid fatigue are common problems among children today. Heel load could be a contributing factor to these problems because it induces deterioration of posture and unnecessary muscle activation.

Children who attend kindergartens following a barefoot policy have fewer untouched toes because they have greater opportunities to move their toes (Matsuda, Kasuga, Hanai, \& Demura, 2016; Matsuda, Kasuga, Hanai, Demura, \& Komura, 2016). As the anterior foot pressure ratio increases as more toes touch the ground, it is hypothesized that children who attend kindergartens following a barefoot policy have a higher anterior foot pressure ratio and do not tend to have heel load. This relation between heel load and kindergarten barefoot policies should be examined to comprehensively assess the meaning and effectiveness of a barefoot policy. Therefore, the present study aimed to clarify this relation.

\section{Methods}

\subsection{Participants}

The participants were 257 preschool children (125 boys and 132 girls) attending kindergartens with a barefoot policy (barefoot group) and 316 preschool children (157 boys and 159 girls) attending kindergartens without a barefoot policy (non-barefoot group). Children were classified in half-year groups by age (e.g., all children who had reached their fifth birthday but were not yet five years and six months old were placed in the 5.0 category). Table 1 and Table 2 show the number of participants in each category and their physical characteristics, respectively.

The participants in the barefoot group did not even wear socks at their kindergarten. The kindergarten staff stated that few accidents or injuries resulted from the barefoot 
Table 1. Number of participants.

\begin{tabular}{ccccccc}
\hline & & 5.0 years old & 5.5 years old & 6.0 years old & 6.5 years old & Total \\
\hline \multirow{3}{*}{ Barefoot group } & Boys & 32 & 33 & 40 & 20 & 125 \\
& Girls & 41 & 32 & 34 & 25 & 132 \\
& Sum & 73 & 65 & 74 & 45 & 257 \\
\hline \multirow{3}{*}{ Non-barefoot group } & Boys & 42 & 41 & 47 & 27 & 157 \\
& Girls & 45 & 45 & 42 & 27 & 159 \\
& Sum & 87 & 86 & 89 & 54 & 316 \\
\hline
\end{tabular}

Table 2. Participants' physical characteristics.

\begin{tabular}{|c|c|c|c|c|c|c|c|c|}
\hline & & & & $\begin{array}{l}5.0 \text { years } \\
\text { old }\end{array}$ & $\begin{array}{l}5.5 \text { years } \\
\text { old }\end{array}$ & $\begin{array}{l}6.0 \text { years } \\
\text { old }\end{array}$ & $\begin{array}{l}6.5 \text { years } \\
\text { old }\end{array}$ & Total \\
\hline \multirow{9}{*}{ Boys } & & \multirow{2}{*}{ Barefoot group } & Mean & 107.3 & 110.4 & 114.7 & 116.8 & 112.0 \\
\hline & & & S.D. & 4.7 & 3.8 & 4.3 & 3.8 & 5.5 \\
\hline & & \multirow{2}{*}{ Non-barefoot group } & Mean & 108.3 & 111.0 & 114.8 & 116.5 & 112.4 \\
\hline & & & S.D. & 4.1 & 4.2 & 4.8 & 4.6 & 5.4 \\
\hline & \multirow{5}{*}{ Body mass (kg) } & \multirow{2}{*}{ Barefoot group } & Mean & 17.6 & 19.0 & 21.3 & 22.1 & 19.9 \\
\hline & & & S.D. & 1.9 & 2.4 & 3.5 & 3.1 & 3.3 \\
\hline & & \multirow{3}{*}{ Non-barefoot group } & Mean & 19.0 & 19.2 & 20.8 & 21.6 & 20.0 \\
\hline & & & & & & & & \\
\hline & & & S.D. & 2.3 & 1.9 & 3.0 & 2.4 & 2.6 \\
\hline \multirow{4}{*}{\multicolumn{2}{|c|}{ Height $(\mathrm{cm})$}} & \multirow{2}{*}{ Barefoot group } & Mean & 107.0 & 110.3 & 113.4 & 114.4 & 110.8 \\
\hline & & & S.D. & 3.0 & 4.3 & 4.6 & 4.7 & 5.1 \\
\hline & & \multirow{2}{*}{ Non-barefoot group } & Mean & 107.8 & 110.7 & 113.7 & 115.3 & 111.4 \\
\hline & & & S.D. & 4.1 & 3.7 & 7.9 & 4.6 & 6.0 \\
\hline \multirow{4}{*}{ Girls } & \multirow{4}{*}{ Body mass (kg) } & \multirow{2}{*}{ Barefoot group } & Mean & 17.3 & 18.6 & 19.2 & 20.0 & 18.6 \\
\hline & & & S.D. & 1.6 & 2.2 & 2.2 & 2.1 & 2.2 \\
\hline & & & Mean & 18.5 & 19.2 & 20.3 & 21.3 & 19.7 \\
\hline & & Non-barefoot group & S.D. & 2.3 & 2.3 & 2.1 & 2.8 & 2.5 \\
\hline
\end{tabular}

Note: S.D., standard deviation.

policy. On the other hand, the participants in the non-barefoot group wore shoes while playing. The type of shoes (sports shoes, sandals, etc.) worn by each child was not particularly designated. In general, children spend five or more hours at their kindergarten on week days. Of course, whether a child goes barefoot or wears socks or shoes while at home depends on the child and his/her family and therefore this factor was not controlled in this study.

The purpose and procedure of this study were explained to the children's parents and kindergarten teachers in detail and informed consent was obtained from each of them before the study began or any measurements were taken. This experimental protocol was approved by the Ethics Committee on Human Experimentation of the Faculty of 
Human Science, Kanazawa University (2012-5).

\subsection{Measurement of Anterior-Posterior Foot Pressure Ratio}

An instrument called Foot view Clinic (Nitta, Japan) was used to measure the anterior-posterior foot pressure ratio; it calculates the anterior-posterior foot pressure ratio based on the area of the foot that is in contact with the instrument when in a standing position (Figure 1). The sampling frequency was $20 \mathrm{~Hz}$. The anterior-posterior ratio refers to the pressure distribution between the anterior and posterior parts of the foot (in the left foot in Figure 1, pressure is $26 \%$ and $74 \%$ in the anterior and posterior part, respectively). The line dividing the foot into anterior and posterior parts was set at the center of the foot length, which was defined as the distance from the back of the heel to the front of the longest toe. Foot length was calculated using a personal computer.

To measure the anterior-posterior foot pressure ratio, participants stood barefoot on the measurement device, with their feet five $\mathrm{cm}$ apart and their hands relaxed at the side of the body. They were instructed to look at a mark located at their eye level and stabilize their posture for as long as possible during measurement. After confirmation of posture stability, a 10-second measurement was initiated. Each participant was measured once, and the mean pressure over the 10 -second period was calculated. The proportion of posterior foot pressure in both feet was selected as the variable for analysis.

Some children were unable to maintain a stable posture or could not continuously focus on the mark as instructed. These children were excluded from the study before measurement.

\subsection{Statistical Analysis}

The means and standard deviations of posterior foot pressure in every age category were calculated as basic statistical values. To examine differences according to group and age, a two-way analysis of variance was conducted. The software package SPSS Statistics 17.0 was used in these analyses, and the level of statistical significance was set at $p<$ 0.05 .

\section{Results}

Table 3 shows the means and standard deviations of posterior foot pressure ratio and

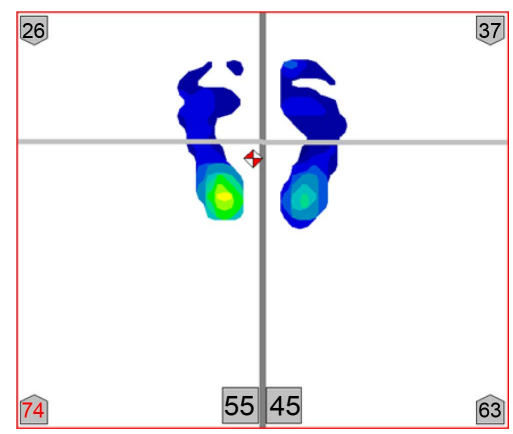

Figure 1. The anterior-posterior foot pressure ratio. 
Table 3. Results of differences among age categories and between barefoot and non-barefoot groups in posterior foot pressure ratio.

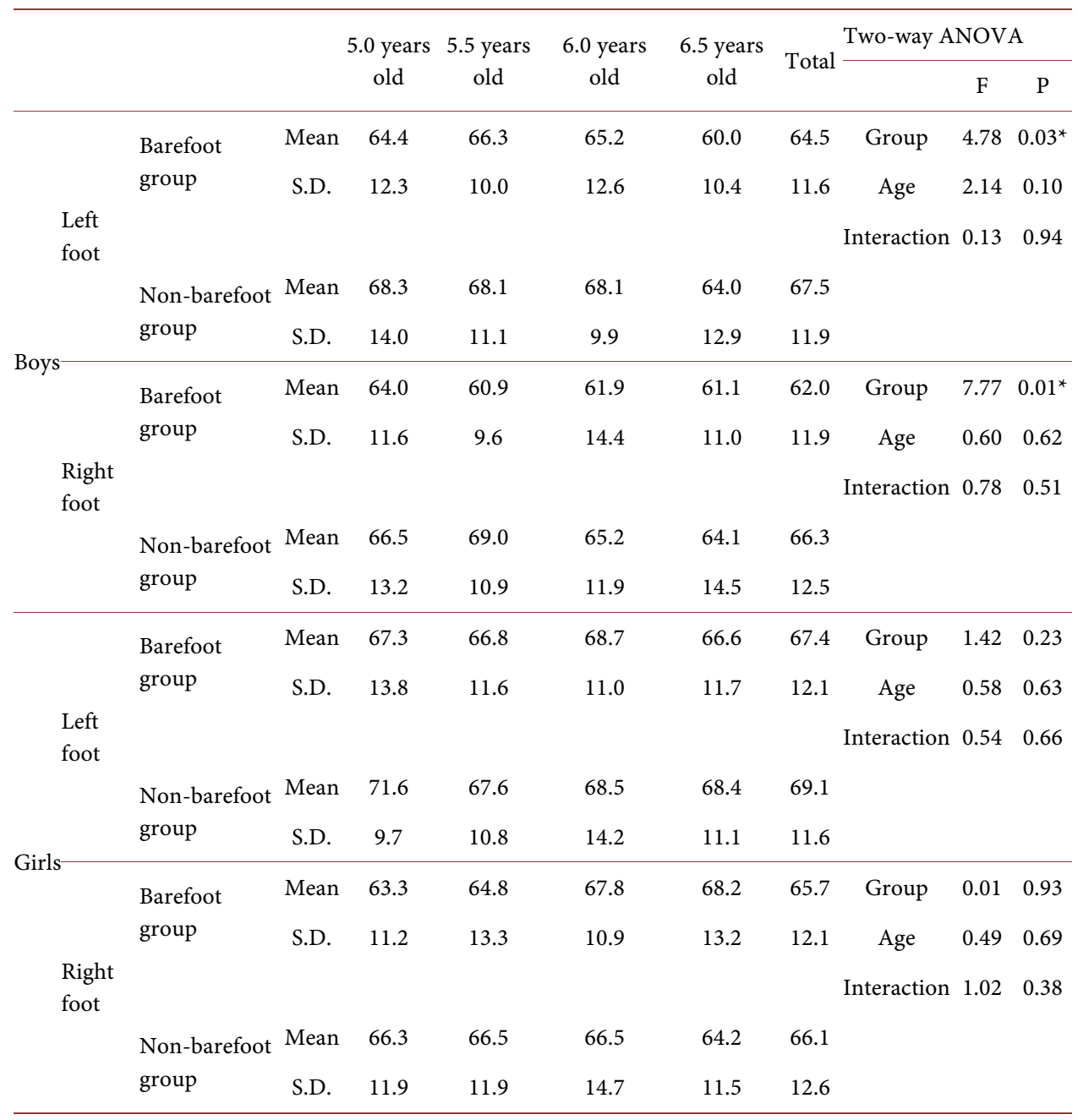

Note: S.D., standard deviation, ${ }^{*}: p<0.05$.

the results of the two-way analysis of variance. For boys, the mean of the posterior foot pressure ratio in the left foot was 64.5 in the barefoot group and 67.5 in the non-barefoot group; in the right foot, the mean was 62.0 in the barefoot group and 66.3 in the non-barefoot group. Differences between the groups were statistically significant. For girls, the mean in the left foot was 67.4 in the barefoot group and 69.1 in the nonbarefoot group; in the right foot, the mean was 65.7 in the barefoot group and 66.1 in the non-barefoot group. There were no statistical differences between the two groups or between age categories for girls.

\section{Discussion}

Heel load, in which children's anterior-posterior foot pressure ratio is weighted toward the posterior of the foot, is undesirable from the viewpoint of their growth and development because anterior foot pressure during standing increases with age (Matsuda \& 
Demura, 2013; Usui et al., 1995). In addition, heel load may be responsible for other physical problems in children, such as inappropriate posture and rapid fatigue. The present study found that boys attending kindergartens with a barefoot policy had a significantly lesser tendency toward heel load. Therefore, kindergartens' barefoot policies appear to affect the anterior-posterior foot pressure ratio positively.

The external pressure on the feet increases when children are wearing shoes. On the other hand, when barefoot, children's feet experience no pressure from shoes and they can thus freely move their toes. Children at kindergartens with a barefoot policy move their toes more often than those in kindergartens without such a policy.

Previous studies have considered the difference in untouched toes between children attending schools with and without a barefoot policy (Matsuda, Kasuga, Hanai, \& Demura, 2016; Matsuda, Kasuga, Hanai, Demura, \& Komura, 2016). At kindergartens with a barefoot policy, the percentage of children with untouched toes and the number of untouched toes were lower in boys (Matsuda, Kasuga, Hanai, \& Demura, 2016). Furthermore, a previous longitudinal study indicated that the number of children without untouched toes increased (from 35.3\% to 64.7\%) among those attending kindergartens with a barefoot policy (Matsuda, Kasuga, Hanai, Demura, \& Komura, 2016). Moreover, it has been reported that elementary school students at schools with a barefoot policy have fewer deformities of their toes (excessive extroversion of the first toe and excessive inversion of the fifth toe) (Enishi, Yamasaki, Hirakawa, Matsunaga, \& Ono, 2008). Therefore, it is inferred that the barefoot policy enables children to have more opportunities for touching their toes to the ground during school hours and that their anterior foot pressure thus increases.

One factor contributing to this result may be related to the difference in walking or running depending on whether one is barefoot or wearing shoes. There are many differences in kinematics and kinetics (how to land, step length, cadence, plantar pressure when the foot is on the ground, etc.) between walking barefoot and while wearing shoes (Franklin, Grey, Heneghan, Bowen, \& Li, 2015; Lorenz \& Pontillo, 2012). In terms of initial contact, for example, runners wearing shoes land using their heels while barefoot runners land using their forefoot (Lieberman et al., 2010). Moreover, the forefoot spreading of the plantar load in the stance phase is larger when one is barefoot (Wolf et al., 2008). Therefore, children attending kindergartens with a barefoot policy are expected to land regularly using their forefoot when walking and running and have a large forefoot spreading of the plantar load in the stance phase. Maintaining this distinction (relative to children who wear shoes when playing in kindergarten) for a long period of time is inferred to result in a difference in the anterior-posterior foot pressure ratio.

On the other hand, no difference was observed between the two groups of girls in this study. This result corresponded to those of previous studies on the relation between untouched toes and kindergartens' barefoot policies (Matsuda, Kasuga, Hanai, \& Demura, 2016; Matsuda, Kasuga, Hanai, Demura, \& Komura, 2016). This finding may be attributable to sex-based differences in the amount of activity in preschool children. Girls tend to be less physically active than boys in kindergarten (Hinkley, Crawford, 
Salmon, Okely, \& Hesketh, 2008). The more one engages in physical activity, the higher the increase in the effect of a kindergarten's barefoot policy on the anterior-posterior foot pressure ratio. Therefore, it is logical to presume that the effect will be weaker among girls than among boys. However, the amount and content of children's physical activity were not measured in this study. This variable should be examined in future studies.

Until the present study, research on the effect of kindergartens' barefoot policies was almost completely limited to foot shape (Asami et al., 1990; Matsuda, Kasuga, Hanai, \& Demura, 2016; Matsuda, Kasuga, Hanai, Demura, \& Komura, 2016). Asami et al. (1990) reported that playing barefoot in kindergarten for five months affected preschool children's foot width and the area of medial longitudinal arch. Furthermore, as stated above, barefoot policy affects the contact between the toes and the ground (Matsuda et al., 2009; Matsuda, Kasuga, Hanai, \& Demura, 2016). The present study clarifies that barefoot policy also affects the anterior-posterior foot pressure ratio, at least among boys. However, the effect of this policy should be examined more comprehensively, since it may also have a broader impact on other important outcomes such as posture, foot strength, and general health.

\section{Conclusion}

This study examined the relation between anterior-posterior foot pressure ratio and kindergartens' barefoot policies by comparing preschool children who attended kindergartens with a barefoot policy and those who attended kindergartens without a barefoot policy. Among boys, posterior foot pressure was significantly lower for those who attended kindergartens with a barefoot policy than for those who did not. On the other hand, no significant difference was observed among girls between the two groups. It appears that kindergartens' barefoot policies affect the anterior-posterior foot pressure ratio and diminish the tendency toward heel load among boys.

\section{Acknowledgements}

The authors wish to thank the subjects for their kind cooperation. This study was supported by a part of JSPS KAKENHI Grant Number 26350951.

\section{Authors' Contributions}

MS controlled this study, performed the experiment, analyzed the data, and wrote the manuscript. KK cooperated with assembling the subjects and conducting the measurement and helped to draft the manuscript. HT and DT cooperated with assembling the subjects and conducting the measurement. FK cooperated with analyzing the data. All authors have read and approved the final version of the manuscript and agree with the order of presentation of the authors.

\section{Competing Interests}

None of the authors declare competing interests. 


\section{References}

Asami, T., Ishijima, S., \& Shibukawa, K. (1990). The Effects of Bare Feet Life on Physical Structure, Function and Feet Sole Shape in Kindergartener. Report of Research Center in Physical Education [in Japanese], 18, 83-94.

Enishi, K., Yamasaki, S., Hirakawa, K., Matsunaga, K., \& Ono, N. (2008). Foot Measurement Result of Elementary School Students Spending School Life Barefoot. KutsunoIgaku [in Japanese], 22, 42-46.

Franklin, S., Grey, M. J., Heneghan, N., Bowen, L., \& Li, F. X. (2015). Barefoot vs Common Footwear: A Systematic Review of the Kinematic, Kinetic and Muscle Activity Differences during Walking. Gait Posture, 42, 230-239. http://dx.doi.org/10.1016/j.gaitpost.2015.05.019

Hinkley, T., Crawford, D., Salmon, J., Okely, A. D., \& Hesketh, K. (2008). Preschool Children and Physical Activity: A Review of Correlates. American Journal of Preventive Medicine, 34, 435441. http://dx.doi.org/10.1016/j.amepre.2008.02.001

Lieberman, D. E., Venkadesan, M., Werbel, W. A., Daoud, A. I., D’Andrea, S., Davis, I. S., Mang'eni, R. O., \& Pitsiladis, Y. (2010). Foot Strike Patterns and Collision Forces in Habitually Barefoot versus Shod Runners. Nature, 463, 531-535. http://dx.doi.org/10.1038/nature08723

Lorenz, D. S., \& Pontillo, M. Z. (2012). Is There Evidence to Support a Forefoot Strike Pattern in Barefoot Runners? A Review. Sports Health, 4, 480-484.

http://dx.doi.org/10.1177/1941738112448055

Matsuda, S., \& Demura, S. (2013). Age-Related, Interindividual, and Right/Left Differences in Anterior-Posterior Foot Pressure Ratio in Preschool Children. Journal of Physiological Anthropology, 32, 8. http://dx.doi.org/10.1186/1880-6805-32-8

Matsuda, S., Demura, S., Kasuga, K., \& Sugiura, H. (2011). Changes in Floating-Toes One Year Later in Preschool Children Based on Longitudinal Data. Japan Journal of Human Growth and Development Research [in Japanese], 51, 19-26.

http://dx.doi.org/10.5332/hatsuhatsu.2011.51 19

Matsuda, S., Demura, S., Kasuga, K., \& Sugiura, H. (2013). Relationship between UntouchedToes and Heel Load in Preschool Children. Advances in Physical Education, 3, 165-168. http://dx.doi.org/10.4236/ape.2013.34027

Matsuda, S., Demura, S., Miyaguchi, K., Kasuga, K., Kitabayashi, T., Aoki, H., \& Yamamoto, Y. (2009). Sex, Age, and Right and Left Differences of Floating-Toe and Its Relationship with Physique in Preschool Children. Journal of Education and Health Science [in Japanese], 54, 198-205.

Matsuda, S., Kasuga, K., Hanai, T., \& Demura, T. (2016). Relationship between Children' Toes and Kindergartens' Barefoot Policy. Advances in Physical Education, 6, 195-204. http://dx.doi.org/10.4236/ape.2016.63021

Matsuda, S., Kasuga, K., Hanai, T., Demura, T., \& Komura, K. (2016). The Effect of the Kindergarten Barefoot Policy on Preschool Children's Toes. Journal of Physiological Anthropology, 36, 4. http://dx.doi.org/10.1186/s40101-016-0097-3

Usui, N., Maekawa, K., \& Hirasawa, Y. (1995). Development of the Upright Postural Sway of Children. Developmental Medicine and Child Neurology, 37, 985-996. http://dx.doi.org/10.1111/j.1469-8749.1995.tb11953.x

Wolf, S., Simon, J., Patikas, D., Schuster, W., Armbrust, P., \& Doderlein, L. (2008). Foot Motion in Children Shoes: A Comparison of Barefoot Walking with Shod Walking in Conventional and Flexible Shoes. Gait Posture, 27, 51-59. http://dx.doi.org/10.1016/j.gaitpost.2007.01.005 
Submit or recommend next manuscript to SCIRP and we will provide best service for you:

Accepting pre-submission inquiries through Email, Facebook, LinkedIn, Twitter, etc. A wide selection of journals (inclusive of 9 subjects, more than 200 journals)

Providing 24-hour high-quality service

User-friendly online submission system

Fair and swift peer-review system

Efficient typesetting and proofreading procedure

Display of the result of downloads and visits, as well as the number of cited articles

Maximum dissemination of your research work

Submit your manuscript at: http://papersubmission.scirp.org/

Or contact ape@scirp.org 